\title{
Heterogeneous Expression and Purification of the Wheat VRN1 K-Box Domain Suggest the Formation of a Tetramer of the VRN1 Protein
}

\author{
Takafumi Itoh ${ }^{1 *}$, Ayane Kamiya', Moe Kimura1, Koji Murai ${ }^{1,2^{*}}$ \\ ${ }^{1}$ Faculty of Bioscience and Biotechnology, Fukui Prefectural University, Fukui, Japan \\ ${ }^{2}$ Department of Sustainable Agri-Culture, Fukui Prefectural University, Fukui, Japan \\ Email: ^ito-t@fpu.ac.jp, ^־urai@fpu.ac.jp
}

How to cite this paper: Itoh, T., Kamiya, A., Kimura, M. and Murai, K. (2021) Heterogeneous Expression and Purification of the Wheat VRN1 K-Box Domain Suggest the Formation of a Tetramer of the VRN1 Protein. American Journal of Plant Sciences, 12, 1002-1010.

https://doi.org/10.4236/ajps.2021.127068

Received: June 8, 2021

Accepted: July 12, 2021

Published: July 15, 2021

Copyright $\odot 2021$ by author(s) and Scientific Research Publishing Inc. This work is licensed under the Creative Commons Attribution International License (CC BY 4.0).

http://creativecommons.org/licenses/by/4.0/

\begin{abstract}
In cereal species such as wheat (Ttiticum aestivum) and barley (Hordeum vulgare), many studies have indicated that VERNALIZATION 1 (VRN1) functions as a flowering promoter, which activates florigen gene expression. The wheat florigen gene Wheat FLOWERING LOCUS T (WFT, which is identical to $V R N 3$ ) is an integrator of the vernalization, photoperiod and autonomous pathways in wheat flowering, and the WFT expression is correlated with the $V R N 1$ expression. $V R N 1$ encodes an APETALA1/FRUITFULL-like MADS-box transcription factor which expression is induced by vernalization, leading to flowering thorough up-regulation of WFT. In Arabidopsis, it has been reported that protein-protein interactions are keys for MADS-box protein function and MADS-box transcription factors must dimerize to bind to the target gene. In this study, by using gel permeation chromatography (GPC) with purified VRN1 protein, we indicated the possibility that VRN1 protein exists as tetramer-like as flowering homeotic MADS-box proteins in Arabidopsis.
\end{abstract}

\section{Keywords}

Flowering, MADS-Box Protein, VRN1, Wheat (Triticum aestivum)

\section{Introduction}

A lot of long-day plant species show an adaptation termed vernalization in which an extended period of low temperature in winter results in the flowering competency during the following spring [1]. Vernalization requirement prevents the plants from transit the reproductive phase before winter when the reproductive 
organs would be damaged by cold temperature. Therefore, vernalization requirement is an important adaptive trait for long-day plants which are germinated in autumn. Interestingly, recent studies have revealed that vernalization systems evolved independently in different plant groups [2]. In temperate cereals, such as wheat (Triticum aestivum) and barley (Hordeum vulgare), three genes have been identified to control the vernalization requirement, namely, $V E R N A L I Z A T I O N 1$ (VRN1), VRN2 and VRN3 [3]. VRN1 and $V R N 2$ are unrelated to the gene with the same name in Arabidopsis.

$V R N 1$ encodes an APETALA1/FRUITFULL-like (AP1/FUL-like) MADS-box transcription factor that is up-regulated by vernalization [4] [5] [6] [7]. Historically, as an ortholog of Arabidopsis floral MADS-box gene AP1 in wheat, WAP1 (wheat $A P 1$, formerly TaMADS\#11, DDBJ accession no. AB007504) was cloned by screening a cDNA library from young spikes of common wheat cv. Norin 26 using the degenerate PCR products corresponding to the MADS box region derived from genomic DNA as probes [8] [9]. WAP1 has three homoeologous genes located on group 5 homoeologous chromosomes, 5A, 5B and 5D [5]. In barley, the $A P 1$ ortholog was firstly reported as BM5 [10]. The barley BM5 shares a high degree of predicted amino acid similarity (95\%) with WAP1 [6]. Then, it was reported that $V R N 1$ located on $5 \mathrm{~A}^{\mathrm{m}}$ chromosome of diploid wheat T. monococcum is $98 \%$ identical with wheat WAP1 [7]. A phylogenetic study of the $A P 1$-like MADS box genes indicated that WAP1 belongs to one close subclade together with TaVRT-1 of wheat [4], VRN1 of T. monococcum [7], BM5 of barley [10] and LtMADS1 of Lolium temulentum [11], suggesting that they are the same gene and the difference of sequence is due to polymorphism.

The level of $V R N 1$ expression is correlated with the level of expression of the wheat florigen gene Wheat FLOWERING LOCUS T (WFT, which is identical to $V R N 3)$ [12] [13]. Expression of $V R N 1$ gradually increases during the seedling growth stage without vernalization [13], suggesting that the expression of $V R N 1$ is also controlled by internal signals such as aging. Furthermore, $V R N 1$ is upregulated under a long photoperiod [5] and shows a diurnal expression pattern that is affected by the length of daylight [12] [13]. These observations indicate that $V R N 1$ expression is controlled by autonomous and photoperiodic pathways as well as by the vernalization pathway. According to the expression and mutant analysis by our research group, $V R N 1$ is thought to up-regulate $W F T$ expression [12]. Recently, we demonstrated that VRN1 proteins directly bind to the promoter region of $W F T$ gene [14], indicating that VRN1 directly up-regulates WFT expression.

In Arabidopsis, it has been known that protein-protein interactions are the key for MADS-box protein function, and floral MADS-box proteins function in vivo as part of tetramers or "floral quartets" (dimers of DNA-binding dimers) [15]. The floral quartet model provides a mechanistic explanation for the $\mathrm{ABCDE}$ model and proposes that the composition of MADS-box protein tetramers is instructive in determining floral organ identity. Actually, it has been demonstrated that the tetramer formed by SEP3 and the MADS protein, AGAMOUS, 
is necessary to activate two target genes, which are required for meristem determinacy [16]. In this study, we revealed the possibility that wheat VRN1 protein exists as tetramer-like as flowering homeotic MADS-box proteins in Arabidopsis.

\section{Materials and Methods}

\subsection{Subcloning of VRN1 K-Box}

Previously, we cloned a full-length cDNA sequence of TaMADS\#11 (VRN-D1) into the pET30c(+) expression vector plasmid [14]. This plasmid was used as a template to generate K-box (His93 to Glu174) expression vector plasmid. The following PCR reaction conditions were used using KOD-plus-Neo DNA polymerase (Toyobo, Osaka, Japan) and appropriate primers (5'-GGAGATATACATATGCACGAATATAGGAAACTG-3' and 5'-GTGGTGGTGCTCGAGCTCGACGAGTTCCTTCTGG-3'): $2 \mathrm{~min}$ at $94^{\circ} \mathrm{C}$, followed by 25 cycles of $10 \mathrm{~s}$ at $98^{\circ} \mathrm{C}, 30 \mathrm{~s}$ at $60^{\circ} \mathrm{C}$, and $30 \mathrm{~s}$ at $68^{\circ} \mathrm{C}$. The PCR fragment was fused into the multi-cloning site (NdeI-XhoI) of pET21b (Merck Millipore, MA) in-frame with the C-terminal His-Tag coding region using In-Fusion HD Cloning Kit (Takara Bio, Otsu, Japan). This subcloned plasmid was then introduced into E. coli BL21-CodonPlus (DE3)-RIL cells.

\subsection{Protein Expression and Purification}

E. coli cells harboring the plasmid were aerobically precultured at $37^{\circ} \mathrm{C}$ in $0.5 \mathrm{~L}$ of Luria-Bertani broth. Once turbidity at $660 \mathrm{~nm}$ reached 0.5 , the culture was supplemented with $1 \mathrm{mM}$ isopropyl- $\beta$-D-thiogalactopyranoside, followed by further incubation at $20^{\circ} \mathrm{C}$ for $20 \mathrm{~h}$. The cultured cells were collected by centrifugation at $6000 \mathrm{~g}$ for $10 \mathrm{~min}$ at $4^{\circ} \mathrm{C}$ and washed with a buffer containing $20 \mathrm{mM}$ sodium phosphate, $\mathrm{pH} 7.4,0.5 \mathrm{M} \mathrm{NaCl}$, and $1 \mathrm{mM}$ phenylmethylsulfonyl fluoride (Buffer A). Cells were then resuspended in the same buffer and ultrasonically disrupted (VCX 750; Sonics \& Materials, CT) at $4^{\circ} \mathrm{C}-8^{\circ} \mathrm{C}$ for $10 \mathrm{~min}$. The cell lysate was centrifuged at $10,000 \mathrm{~g}$ for $20 \mathrm{~min}$ at $4^{\circ} \mathrm{C}$ and the supernatant was collected. The supernatant was applied to a Ni-immobilized metal affinity chromatography column (HisTrap HP column, $5 \mathrm{ml}$; GE Healthcare, WI) pre-equilibrated with $20 \mathrm{mM}$ imidazole in Buffer A. The column-bound protein was eluted on a linear imidazole gradient (20 to $250 \mathrm{mM}$ ) in Buffer A (50 ml). Fractions containing the protein $(<15 \mathrm{ml})$ were concentrated by Amicon Ultra-15 concentrator with a 10,000 molecular weight cutoff membrane (Merck Millipore) to a volume of about 1 - $2 \mathrm{ml}$. The concentrated fraction was applied to a gel permeation chromatography Superdex 200 10/300 GL column (24 ml; GE Healthcare) preequilibrated with $10 \mathrm{mM}$ tris(hydroxymethyl)aminomethane (Tris), $\mathrm{pH}$ 7.5, 0.5 $\mathrm{M} \mathrm{NaCl}, 1 \mathrm{mM}$ dithiothreitol (DTT). Fractions containing K-box were collected as the purified protein. Protein concentrations were determined using a Bradford Protein Assay kit (Bio-Rad, CA), with bovine serum albumin as the standard, or by UV spectrophotometry using the molar extinction coefficient $\varepsilon_{280}=$ 
$1490\left(\mathrm{M}^{-1} \cdot \mathrm{cm}^{-1}\right)$ according to ExPASy ProtParam tool server (http://web.expasy.org/protparam/) [17]. The protein was purified to homogeneity, as determined by $15 \%$ sodium lauryl sulfate polyacrylamide gel electrophoresis (SDS-PAGE) analysis followed by Coomassie Brilliant Blue (CBB) R-250 staining.

\subsection{Gel Permeation Chromatography}

The purified VRN1 K-box was dialyzed at $4^{\circ} \mathrm{C}$ overnight against $10 \mathrm{mM} 4$ (2-hydroxyethyl)piperazine-1-(ethanesulfonic acid) (HEPES), $0.5 \mathrm{M} \mathrm{NaCl}, 1$ $\mathrm{mM}$ DTT to remove Tris salt. The protein solution $(3.5 \mathrm{mg} / \mathrm{ml}, 20 \mu \mathrm{l})$ was mixed with glutaraldehyde solution $(2.5 \% \mathrm{v} / \mathrm{v}, 1 \mu \mathrm{l})$ or water $(1 \mu \mathrm{l})$. After incubation at $20^{\circ} \mathrm{C}$ for $1 \mathrm{~min}$, the reaction was stopped by adding $2 \mu \mathrm{l}$ of $1 \mathrm{M}$ Tris, $\mathrm{pH}$. The aliquot $(10 \mu \mathrm{l})$ was mixed with $10 \mu \mathrm{l}$ of $2 \times$ SDS-PAGE sample loading buffer and heated at $100^{\circ} \mathrm{C}$ for $10 \mathrm{~min}$. The samples $(10 \mu \mathrm{l}, 15 \mu \mathrm{g}$ protein) were visualized by SDS-PAGE and CBB R-250 staining. The molecular size of the purified K-box protein was analyzed by gel permeation chromatography (GPC) using the same procedure for the purification method.

\section{Results and Discussion}

MADS-box proteins are defined by a unique domain structure: in addition to the highly conserved DNA-binding MADS-domain, they have three other domains ("I", " $\mathrm{K}$ " and "C"), with the keratin-like K-domain being the most highly conserved and characteristic one [18]. The K-domain mediates protein-protein interaction and is postulated to form several amphipathic a-helices referred to as K1, K2, and K3 [19]. To determine whether wheat VRN1 protein forms multimers, we performed in vitro assay to examine the protein-protein interaction of VRN1 using purified K-box domain. From our previous preliminary experiments, we have found that the VRN1 full-length protein is very unstable for an unknown reason. Therefore, in this study, we used K-box domain which is involved in protein-protein interaction.

At first, we subcloned K-box from a full-length cDNA sequence of TaMADS\#1 1 ( $V R N-D 1)$ [9] [14]. Then we constructed E. coli protein expression vector (Figure 1(a)) which was introduced into $E$. coli cells. Proteins produced by $E$. coli cells were purified and analyzed by sodium lauryl sulfate polyacrylamide gel electrophoresis (SDS-PAGE) (Figure 1(b)). The SDS-PAGE image indicates purified K-box proteins.

Next, we performed cross-linking assay of the K-box proteins by using glutaraldehyde and SDS-PAGE assay (Figure 2). The SDS-PAGE images clearly show monomer, dimer, trimer and tetramer of the K-box proteins. Among these multimers, the dimer was the major product. It is suggested that the K-box forms a dimeric or larger complex. The molecular size of the purified K-box protein was analyzed by gel permeation chromatography (GPC) using the same procedure for the purification method (Figure 3, black line). The main peak of the 


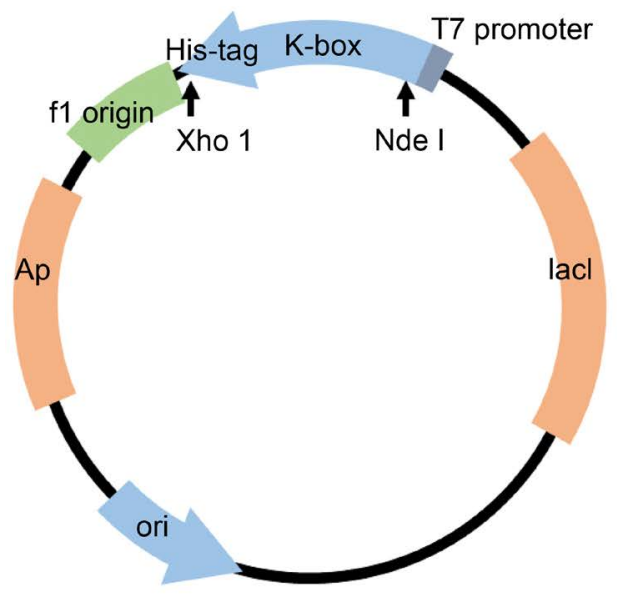

(a)

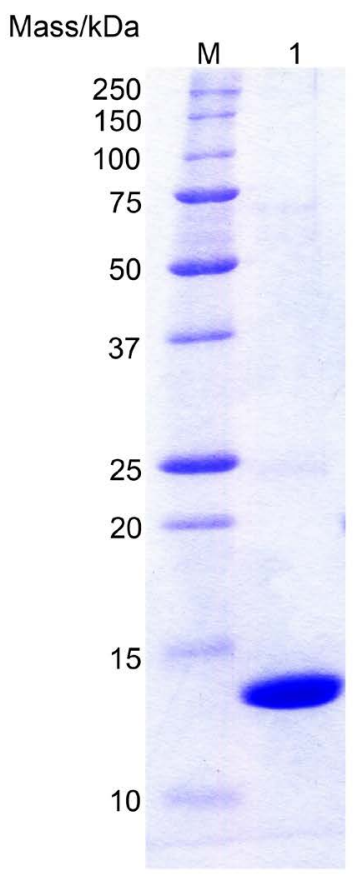

(b)

Figure 1. (a) Construction of the expression vector plasmid pET21b with K-box fusion driven by the T7 promoter. A DNA encoding K-box domain of VRN-D1 was cloned in-frame into the NdeI-XhoI cloning site. The plasmid has an f1 origin, a pBR322 origin (ori), Ap (ampicillin resistance, $\beta$-lactamase), and lacI gene. (b) SDS-PAGE image in which protein bands were stained with CBB R-250. Lane M, molecular mass standards; lane 1, purified K-box $(1 \mu \mathrm{g})$. Notice that it shows molecular weight of the VRN1 K-box protein with His-tag.

glutaraldehyde treated (cross-linked) multimeric mixture (Figure 3, red line), which was determined to be a dimer by SDS-PAGE, eluted later than the purified K-box protein (before cross-linking). The shape of the dimeric form after cross-linking was suggested to be compact. Assuming that no major conformational change occurred before and after cross-linking, the purified K-box protein is likely to exist in a tetramer formation based on the elution positions of the 


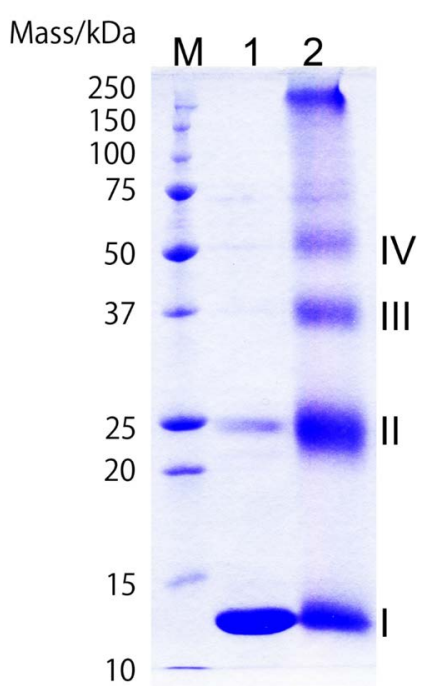

Figure 2. SDS-PAGE images for glutaraldehyde cross-linking experiment. K-box was incubated in the presence of glutaraldehyde $(0.12 \% \mathrm{v} / \mathrm{v})$ to stabilize the possible oligomeric forms of the protein. The cross-linked K-box was analyzed by SDS-PAGE. Lane M, molecular mass standards; lane 1, purified K-box (15 $\mu \mathrm{g}$, control); lane 2, the cross-linked K-box $(15 \mu \mathrm{g})$. Roman numerals I-IV correspond to the monomer to tetramer of K-box protein, respectively.

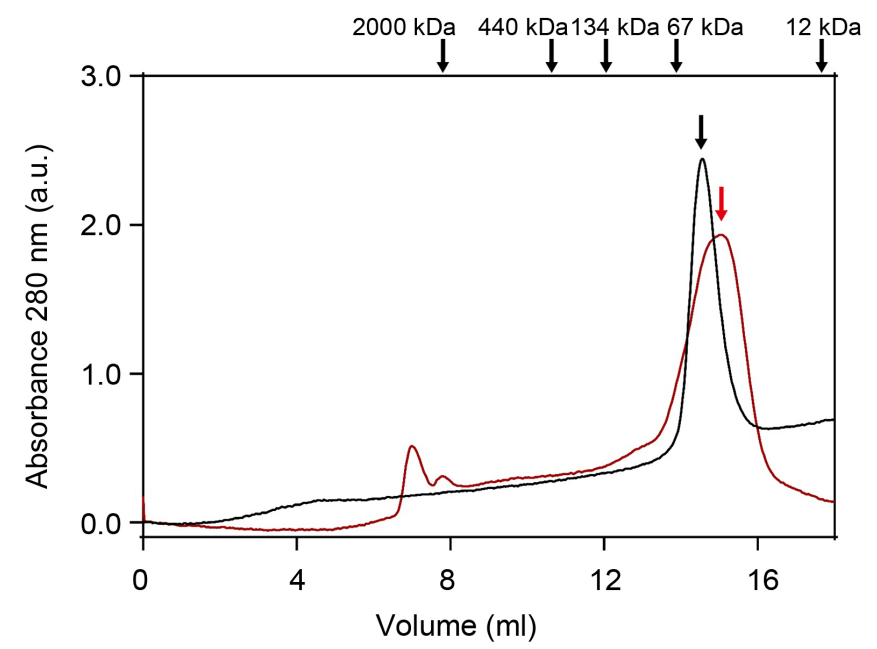

Figure 3. Gel permeation chromatography analysis of purified K-box protein (black line). Red line indicates the glutaraldehyde treated (cross-linked) multimeric mixture. The peaks are shown by black and red arrow, respectively. The elution positions of molecular mass markers are also shown; blue dextran (GE Healthcare), molecular mass $=2000 \mathrm{kDa}$; horse spleen ferritin, $440 \mathrm{kDa}$; bovine serum albumin dimer, $134 \mathrm{kDa}$; monomer, $67 \mathrm{kDa}$; pigeon cytochrome C, $12 \mathrm{kDa}$; vitamin $\mathrm{B} 2,376 \mathrm{Da}$.

external standards. The elution positions of the external standards (blue dextran (GE Healthcare), molecular mass $=2000 \mathrm{kDa}$; horse spleen ferritin, $440 \mathrm{kDa}$; bovine serum albumin dimer, $134 \mathrm{kDa}$; monomer, $67 \mathrm{kDa}$; pigeon cytochrome C, $12 \mathrm{kDa}$; vitamin $\mathrm{B} 2,376 \mathrm{Da}$ ) indicate the purified K-box protein exists as a tetramer formation.

We have been presenting the model in which $V R N 1$ directly activates WFT 
expression since 2009 [12]. In this model, $V R N 1$ is upstream of $W F T$ and the VRN1 protein directly up-regulates WFT expression by binding to the promoter region. This model is consistent with the concept that the level of $V R N 1$ expression functions as a threshold for flowering competency in wheat [13]. By using a chromatin immunoprecipitation (ChIP)-seq analysis, VRN1-binding target genes were identified [20]. A total of 289 binding peaks were identified for predicted genes associated with transcribed sequences; one of these was barley FT. This result suggests that VRN1 protein binds to the promoter region of the FT gene. Finally, we demonstrated that VRN-D1 proteins directly bind competitively and specifically to the CArG-box region in the promoter region of WFT-D gene [14]. In this study, we firstly indicated the possibility that the cereal VRN1 MADS-box protein functions as tetramer, especially homo-tetramer, to up-regulate WFT gene. In Arabidopsis, it is known that the hetero-tetramer network of MADS transcription factors play important roles in a lot of biological processes [21]. If wheat VRN1 protein actually forms homo-tetramers and functions in vivo, its mechanism of action is very interesting. The present result will be a clue to elucidate the function of VRN1 protein, that is, how to up-regulate WFT expression, in a flowering pathway of wheat.

\section{Acknowledgements}

We are grateful to the National Bioresource Project-Wheat (NBRP-KOMUGI) for providing the wheat cultivar. This work was supported in part by the Grantin-Aid for Scientific Research (B) from The Ministry of Education, Culture, Sports, Science and Technology (MEXT) KAKENHI Grant Number $18 \mathrm{H} 02180$ to K. Murai. This work was also supported in part by a Grant-in-Aid (D) from Fukui Prefectural University to K. Murai.

\section{Conflicts of Interest}

The authors declare no conflicts of interest regarding the publication of this paper.

\section{References}

[1] Kim, D.H., Doyle, M.R., Sung, S. and Amasino, R.M. (2009) Vernalization: Winter and the Timing of Flowering in Plants. Annual Review of Cell Developmental Biology, 25, 277-299. https://doi.org/10.1146/annurev.cellbio.042308.113411

[2] Ream, T.S., Woods, D.P. and Amasino, R.M. (2013) The Molecular Basis of Vernalization in Different Plant Groups. Cold Spring Harbor Symposium of Quantitative Biology 2012, 77, 105-115. https://doi.org/10.1101/sqb.2013.77.014449

[3] Travaskis, B., Hemming, M.N., Dennis, E.S. and Peacock, W.J. (2007) The Molecular Basis of Vernalization-Induced Flowering in Cereals. Trends in Plant Science, 12, 352-357. https://doi.org/10.1016/j.tplants.2007.06.010

[4] Danyluk, J., Kane, N.A., Breton, G., Limin, A.E., Fowler, D.B. and Sarhan, F. (2003) TaVRT-1, a Putative Transcription Factor Associated with Vegetative to Reproductive Transition in Cereals. Plant Physiology, 132, 1849-1860.

https://doi.org/10.1104/pp.103.023523 
[5] Murai, K., Miyamae, M., Kato, H., Takumi, S. and Ogihara, Y. (2003) WAP1, a Wheat APETALA1 Homolog, Plays a Central Role in the Phase Transition from Vegetative to Reproductive Growth. Plant and Cell Physiology, 44, 1255-1265. https://doi.org/10.1093/pcp/pcg171

[6] Trevaskis, B., Bagnall, D.J., Ellis, M.H., Peacock, W.J. and Dennis, E.S. (2003) MADS Box Genes Control Vernalization-Induced Flowering in Cereals. Proceedings of the National Academy of Sciences of the United States of America, 100, 13099-13104. https://doi.org/10.1073/pnas.1635053100

[7] Yan, L., Loukoianov, A., Tranquilli, G., Helguera, M., Fahima, T. and Dubcovsky, J. (2003) Positional Cloning of the Wheat Vernalization Gene VRN1. Proceedings of the National Academy of Sciences of the United States of America, 100, 6263-6268. https://doi.org/10.1073/pnas.0937399100

[8] Murai, K., Murai, R. and Ogihara, Y. (1997) Wheat MADS Box Genes, a Multigene Family Dispersed Throughout the Genome. Genes and Genetic Systems, 72, 317-321. https://doi.org/10.1266/ggs.72.317

[9] Murai, K., Murai, R., Takumi, S. and Ogihara, Y. (1998) Cloning and Characterization of cDNAs Corresponding to the Wheat MADS Box Genes. Proceedings of 9 th International Wheat Genetic Symposium, Vol. 1, Saskatoon, 2-9 August 1998, 89-94.

[10] Schmitz, J., Franzen, R., Ngyuen, T. H., Garcia-Maroto, F., Pozzi, C., Salamini, F. and Rohde, W. (2000) Cloning, Mapping and Expression Analysis of Barley MADS-Box Genes. Plant Molecular Biology, 42, 899-913. https://doi.org/10.1023/A:1006425619953

[11] Gocal, G.F.W., King, R.W., Blundell, C.A., Schwartz, O.M., Andersen, C.H. and Weigel, D. (2001) Evolution of Floral Meristem Identity Genes. Analysis of Lolium temulentum Genes Related to APETALA1 and LEAFY of Arabidopsis. Plant Physiology, 125, 1788-1801. https://doi.org/10.1104/pp.125.4.1788

[12] Shimada, S., Ogawa, T., Kitagawa, S, Suzuki, T., Ikari, C., Shitsukawa, N., Abe, T., Kawahigashi, H., Kikuchi, R., Handa, H., et al. (2009) A Genetic Network of Flowering Time Genes in Wheat Leaves, in Which an APETALA1/FRUITFULL-Like Gene, VRN1, Is Upstream of Flowering locus T. The Plant Journal, 58, 668-681. https://doi.org/10.1111/j.1365-313X.2009.03806.x

[13] Nishiura, A., Kazama, Y., Abe, T., Mizuno, N., Nasuda, S. and Murai, K. (2014) Level of VERNALIZATION 1 Expression Is Correlated with Earliness in Extra Early-Flowering Mutant Wheat Lines. Breeding Science, 64, 213-221. https://doi.org/10.1270/jsbbs.64.213

[14] Tanaka, C., Itoh, T., Iwasaki, Y., Mizuno, N., Nasuda, S. and Murai K. (2018) Direct Interaction between VRN1 Protein and the Promoter Region of the Wheat FT Gene. Genes and Genetic Systems, 93, 25-29. https://doi.org/10.1266/ggs.17-00041

[15] Theißen, G., Melzer, R. and Rümpler, F. (2016) MADS-Domain Transcription Factors and the Floral Quartet Model of Flower Development: Linking Plant Development and Evolution. Development, 143, 3259-3271.

https://doi.org/10.1242/dev.134080

[16] Hugouvieux, V., Silva, C.S., Jourdain, A., Stigliani, A., Charras, Q., Conn, V., Conn, S.J., Carles, C.C., Parcy, F. and Zubieta, C. (2018) Tetramerization of MADS Family Transcription Factors SEPALLATA3 and AGAMOUS Is Required for Floral Meristem Determinacy in Arabidopsis. Nucleic Acids Research, 46, 4966-4977. https://doi.org/10.1093/nar/gky205

[17] Gasteiger, E., Hoogland, C., Gattiker, A., Duvaud, S., Wilkins, M.R., Appel, R.D. and Bairoch, A. (2005) Protein Identification and Analysis Tools on the ExPASy 
Server. In: Walker, J.M., Ed., The Proteomics Protocols Handbook, Humana Press, New York, 571-607. https://doi.org/10.1385/1-59259-890-0:571

[18] Kaufmann, K., Melzer, R. and Theißen, G. (2005) MIKC-Type MADS-Domain Proteins: Structural Modularity, Protein Interactions and Network Evolution in Land Plants. Gene, 347, 183-198. https://doi.org/10.1016/j.gene.2004.12.014

[19] Yang, Y. and Jack, T. (2004) Defining Subdomains of the K Domain Important for Protein-Protein Interactions of Plant MADS Proteins. Plant Molecular Biology, 55, 45-59. https://doi.org/10.1007/s11103-004-0416-7

[20] Deng, W., Casao, M.C., Wang, P., Sato, K., Hayes, P.M., Finnegan, E.J. and Trevaskis, B. (2015) Direct Links between the Vernalization Response and Other Key Traits of Cereal Crops. Nature Communications, 6, Article No. 5882. https://doi.org/10.1038/ncomms6882

[21] Espinosa-Soto, C., Immink, R.G.H., Angenent, G.C., Alvarez-Buylla, E.R. and de Folter, S. (2014) Tetramer Formation in Arabidopsis MADS Domain Proteins: Analysis of a Protein-Protein Interaction Network. BMC Systems Biology, 8, Article No. 9. https://doi.org/10.1186/1752-0509-8-9 